\title{
Anal dysplasia detection during routine screening colonoscopy
}

\author{
Michelle D Inkster and James S Wu* \\ Digestive Diseases and Surgery Institute, Cleveland Clinic, Cleveland, Ohio, USA
}

\begin{abstract}
Introduction: Anal squamous intraepithelial lesion precedes anal cancer. Inspection of the epithelium at risk for anal dysplasia is an integral part of routine screening colonoscopy. Detection of anal squamous intraepithelial lesions during screening colonoscopy is possible using standard techniques and currently available instruments.

Results: Fifteen low-grade and 10 high-grade squamous intraepithelial lesions were found incidentally at screening colonoscopy in 25 patients [F/M $16 / 9$; median age 59 (46-82)]. A review of the medical record did not reveal risk factors for anal squamous cell cancer. Thirteen low-grade and 12 high-grade lesions subsequently were identified by chromoendoscopy with narrow band imaging/acetic acid and ablated.

Conclusions: Anal squamous intraepithelial lesions can be detected at routine screening colonoscopy. Screening for anal SIL is an integral part of every colonoscopic examination since the at-risk epithelium is crossed at the beginning and at the end of every procedure. Focused examination of the ATZ and anal canal during routine screening colonoscopy affords an opportunity to increase detection of anal SIL, the precursor to anal squamous cell carcinoma. Lesions detected can reproducibly be reidentified and ablated by chromoendoscopy using techniques and instruments familiar to all endoscopists.
\end{abstract}

Abbreviations: WL: White light; NBI: Narrow band imaging; EF: En face; RF: Retroflexed; AA: Acetic acid, A: Anterior, L: Left; R: Right; Scope/S: Colonoscope; ARL: Anorectal line; ATZ: Anal transitional zone

\section{Introduction}

Examination of the anal epithelium at-risk for anal squamous intraepithelial lesion (SIL) and anal cancer is an integral part of routine screening colonoscopy. In order to reach the columnar epithelium atrisk for colorectal cancer, the colonoscope must traverse the perianal skin, the anal pecten and the anal transitional zone (ATZ). The anoderm is readily inspected using en face (EF) and retroflexed (RF) views with and without narrow band imaging (NBI). The endoscopic appearance of anal cancer and its precursor, anal SIL has been described [1-4]. Anal SIL detected by biopsy of suspicious lesions can be ablated.

\section{Methods}

In 2011, approval was obtained from the Cleveland Clinic Institutional Review Board to identify and evaluate all patients within our Health System who had received the diagnosis of anal SIL. In this non-randomized prospective study, anal SIL was diagnosed incidentally at screening colonoscopy for colorectal cancer. Followup chromoendoscopy to detect and ablate anal SIL was performed as described previously using high definition gastroscopes (Olympus GHF 180/190) [5,6]. In the chromoendoscopic examination, the ATZ and anal pecten were inspected using EF and RF views with white light (WL) and NBI before and after treatment of the ATZ and anoderm with $3 \%$ acetic acid (AA). The anal canal was viewed with the endoscope $\mathrm{EF}$ with and without a self-lighted beveled Anospec ${ }^{\mathrm{TM}}$ anoscope. Features consistent with SIL were noted [7]. Photo-documentation was preserved as part of the permanent electronic medical record
(Provation $^{\mathrm{TM}}, \mathrm{EPIC}^{\mathrm{TM}}$ ). Histopathology was reported according to the Lower Anogenital Squamous Terminology (LAST) standardization project for HPV-associated lesions [8].

\section{Results}

Between 2011 and 2018, anal SIL was detected in 25 patients at screening colonoscopy for colorectal cancer. A review of the medical record did not reveal risk factors for anal cancer. Patient demographics are shown in Table 1. Ten patients were identified by the authors; 15 patients were referred to the authors for management of anal SIL detected by other endoscopists. Pathology of lesions biopsied at screening colonoscopy is shown in Table 2 . All patients subsequently underwent chromoendoscopy with EF and RF views using NBI and AA under conscious sedation to reidentify, biopsy and ablate anal SIL; pathology of lesions biopsied and ablated are shown in Table 3.

On rebiopsy, the diagnosis changed from LSIL to HSIL in three patients and from HSIL to LSIL in one patient.

During routine colonoscopy, the epithelium at risk for anal HPV infection (perianal skin, pecten, ATZ) is examined. The normal endoscopic appearance of the ATZ and pecten, seen with RF and EF views, is shown in Figures 1a, b, c (Figure 1).

${ }^{\star}$ Correspondence to: James S Wu, Digestive Diseases and Surgery Institute, Cleveland Clinic, 20050 Harvard Road, Warrensville Heights, OH 44128, USA, Tel: 216-491-7861; E-mail: wuj@ccf.org

Key words: Anal dysplasia, Squamous intraepithelial lesion, screening colonoscopy, human papillomavirus, chromoendoscopy, narrow band imaging

Received: September 04, 2018; Accepted: September 10, 2018; Published: September 12, 2018 

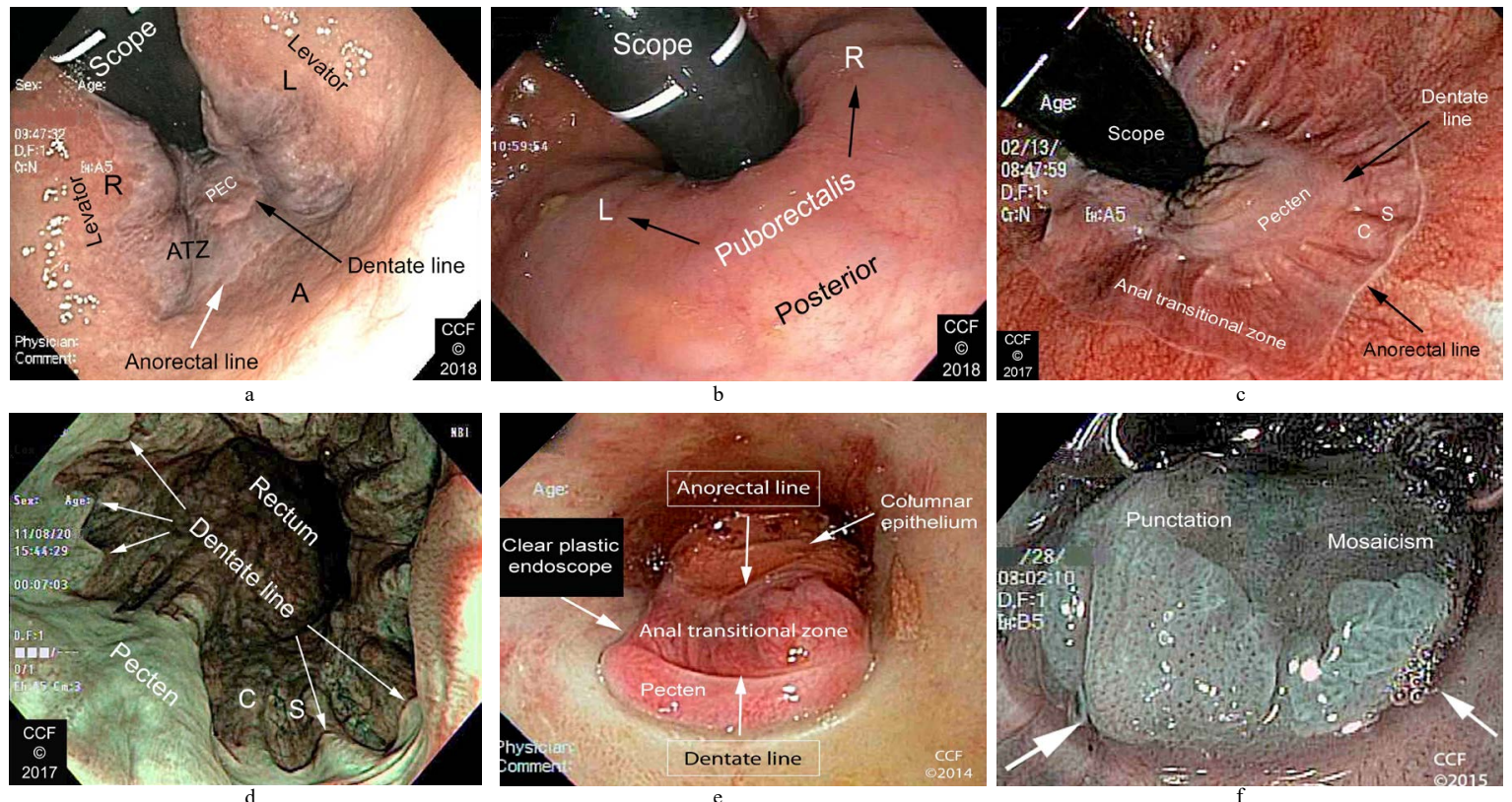

Figure 1. a. Distal rectum, RF, anterior view. The anorectal line (white arrow), ATZ, dentate line (black arrow), pecten (PEC) and the contour of the levator ani muscles are seen. Right (R), left (L) and anterior (A) positions are labelled; b. distal rectum, RF, posterior view. The contour of the puborectalis is seen. The ATZ and pecten are not seen; c. On this anterior view, the ATZ, pecten, and columns/sinuses of Morgagni are seen on retroflexion with WL; d. EF view of the anal canal seen with NBI. The pecten, dentate (pectinate) line and columns/sinuses of Morgagni (C, S) are seen (The terms pectinate and dentate are derived from the scalloped or toothlike appearance of the distal border of the ATZ); e. EF view of the pecten, ATZ and columnar epithelium seen through a lighted beveled clear plastic anoscope; f. This anoscopic view of anal LSIL with NBI demonstrates punctuation and mosaicism similar to that seen in colonic polyps

Table 1. Demographics. 25 patients with anal SIL detected incidentally at routine screening colonoscopy

\begin{tabular}{|c|c|}
\hline Female/male & $16 / 9$ \\
\hline Age & Median 59(range 46-82) \\
\hline
\end{tabular}

Table 2. Anal SIL detected incidentally on colonoscopy in 25 patients

\begin{tabular}{|c|c|}
\hline Pathology & N \\
\hline LSIL & 15 \\
\hline HSIL & 10 \\
\hline
\end{tabular}

Table 3. Anal SIL identified, biopsied and ablated by chromoendoscopy with en face and retroflexed views in 25 patients

\begin{tabular}{|c|c|}
\hline Pathology & N \\
\hline LSIL & 13 \\
\hline HSIL & 12 \\
\hline
\end{tabular}

Examples of anal SIL detected in patients included in this study are shown in Figure 2. Endoscopic features of anal SIL include acetowhite changes, punctuation and mosaicism. Lesions may be raised or flat [7].

\section{Discussion}

Anal squamous cell cancer (SCC) and its precursor lesion, anal SIL are HPV-related neoplasms [9-11]. The National Cancer Institute, Surveillance, Epidemiology, and End Results (SEERS) Program estimated 8,580 new cases of anal cancer in the United States in the year 2018 with rates for new anal cancer cases rising on average $2.2 \%$ each for the last 10 years [12]. The United States Department of Veterans Affairs recommends screening at-risk populations for anal cancer including HPV-infected men and women, particularly MSM (with or without HIV infection), any patient with a history of anogenital condyloma, and women with abnormal cervical or vulvar histology [13]. At risk populations not included in current screening recommendations include those with inflammatory bowel disease, collagen vascular disease and solid organ transplantation recipients as well as patients who have had exposure to HPV but who are asymptomatic [14]. According to the national Survey for Endoscopic Capacity about 15 million colonoscopies were done in the United States in 2012 for colorectal cancer screening [15]. Most teaching documents on the subject of colonoscopy focus on its role in the detection of adenomas to prevent colorectal cancer. Omitted is the role of colonoscopy in the detection of anal SIL and anal SCC despite the fact that examination of the epithelium at risk for anal SIL and anal cancer (the anal pecten and the ATZ) must be traversed in order to reach the columnar epithelium at risk for colorectal cancer.

\section{Anatomic considerations}

Nigro stated in 1987, that the ATZ is the site where anal cancer begins based on its cloacogenic origin, an origin that it shares with the cervical transformation zone [16]. In 1986, Fenger and Nielsen described three histologic zones of the anal canal, the colo-rectal mucosa, the ATZ above the dentate line and the squamous zone below [17]. In 1987, Fenger published an extensive description of the ATZ [18]. The proximal border of the anal transitional zone is the anorectal line described by Herrmann and Desfosses in 1880 [19]. Distal to the dentate line is the pecten, squamous epithelium, defined by Stroud in 1904 [20]. The anal verge is the junction of non-keratinized squamous epithelium of the anal canal with hair-bearing, keratinized, perianal skin [21]. External to the anal verge is the perianal skin or anal margin. In 2012, Tanaka et al. demonstrated the epithelial landmarks of the anoderm endoscopically (Figure 3) [22]. These anatomic landmarks are recognized easily by trained practitioners. Because of the anterior opening in the levator sling, the anterior ATZ usually is seen, especially during retroflexion with rectal insufflation. The posterior ATZ often is not seen on retroflexion because it lies distal to the anorectal ring 

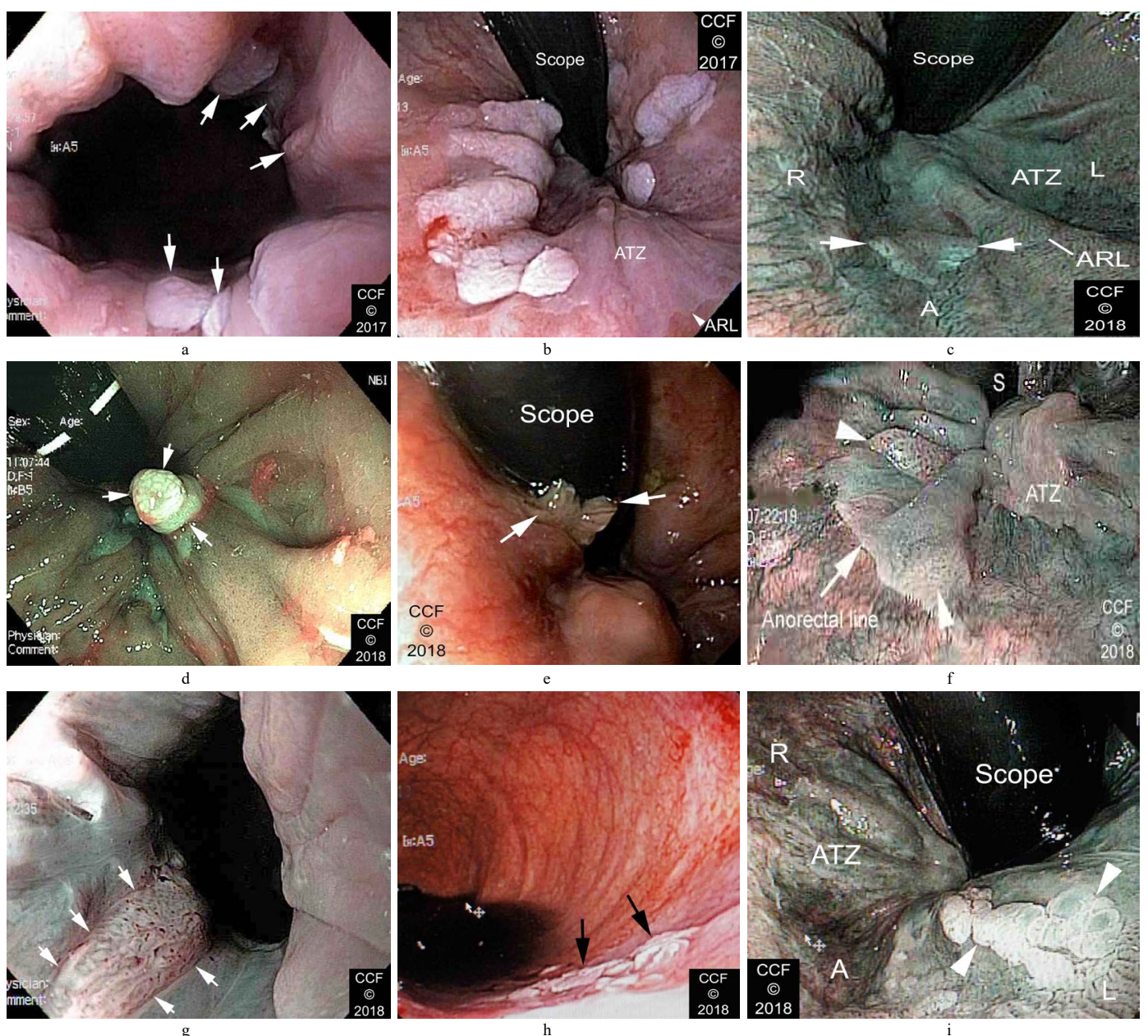

Figure 2. a. Multiple ATZ lesions are partially seen on EF view with WL; b. (same patient as in Figure 2a) On anterior RF view with WL, multiple discrete lesions are seen. The ATZ and ARL are marked. Biopsy showed LSIL; c. This subtle slightly raised anterior ATZ lesion with punctuation (arrows) was seen on RF view with NBI. Pathology showed LSIL; d. RF view of a small lesion resembling an anal papilla under NBI illumination showed distinct vascular mosaicism. Biopsy showed LSIL; e. A bilobed raised lesion (arrows) with prominent vessels seen on RF view with WL. Biopsy showed HSIL; f. Retroflexed view of the ATZ with NBI, shows areas of punctation (arrowheads). The colonoscope is seen at the top of the image (S). Biopsies showed HSIL; g. EF view of an anal canal lesion seen with NBI (arrows). Biopsies showed HSIL; h. A cluster of flat distal rectal lesions seen EF during WL colonoscopy; i. Repeat $\mathrm{RF}$ examination of the patient in Figure $2 \mathrm{~h}$ with NBI and AA shows an acetowhite cluster of lesions on the left ATZ. Biopsy showed HSIL

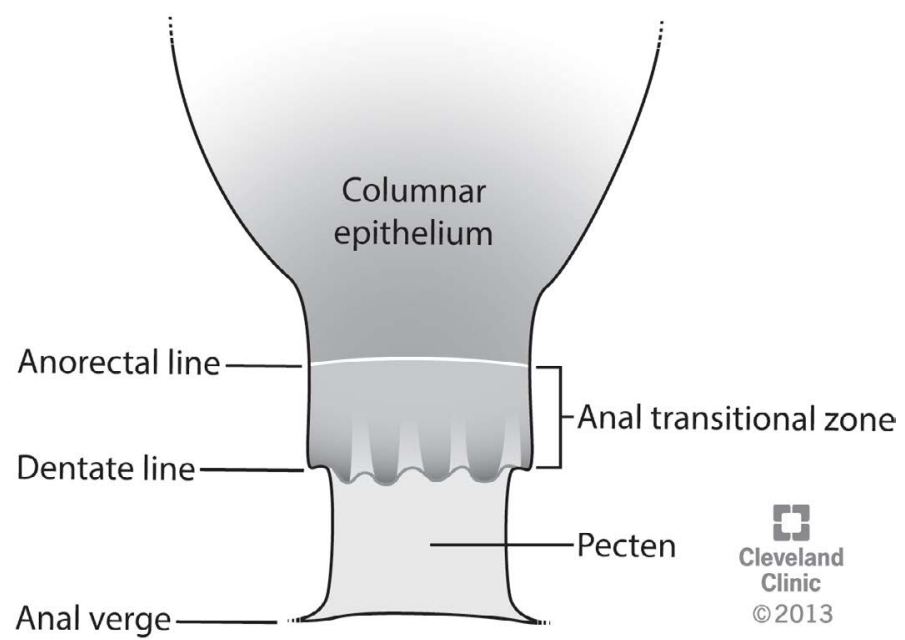

Figure 3. Anatomic features of the anal canal epithelium. The colorectal columna epithelium meets the proximal border of the ATZ at the anorectal line of Herrmann and Desfosses. The ATZ meets the pecten of Stroud at the dentate/pectinate line. Within the ATZ are the columns and sinuses of Morgagni beneath which lie hemorrhoidal vessels. The pecten meets the hair bearing perianal skin at the anal verge defined by the puborectalis muscle. The pecten is seen on introduction and withdrawal of the endoscope. Colonoscopy, therefore, can detect neoplastic lesions of the epithelia at risk for both colorectal cancer and anal cancer in a single examination.

\section{Retroflexion}

Grobe evaluated retroflexion to look for 'rectal disease' as rectal retroflexion had not been studied as a diagnostic maneuver [23]. The procedure that we use to detect anal lesions for patients with risk factors can also be used to detect lesions during routine colonoscopy. It requires that retroflexion be done where safe and that the area be viewed in both white light and after using the narrow band imaging available with current high definition colonoscopes. The important point is to retroflex and then rotate as illustrated in Figure 4.

Water can be used to orient the lesions so that the same area can be viewed on future procedures. Water is always in the dependent position. In the anterior view the water would be on the right side of the photograph when the patient is lying on the left side.

In 1999, Dr. Jerome Waye, one of the pioneers in the field of endoscopy, in his article 'What constitutes a total colonoscopy?' wrote 

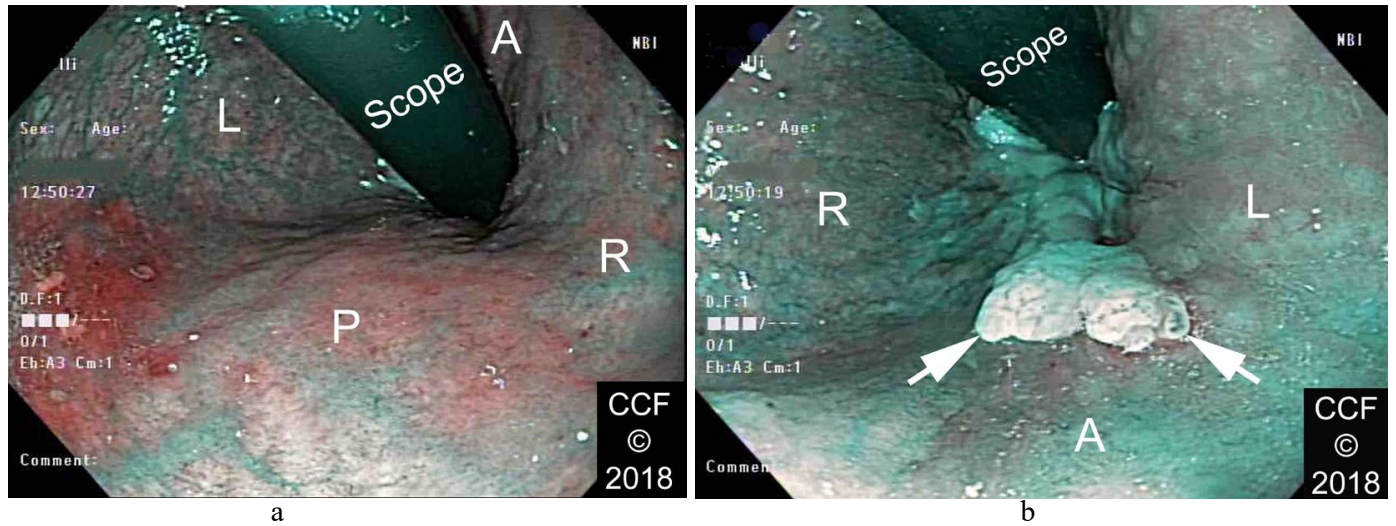

Figure 4. a. shows the posterior retroflexed view of the rectum with NBI - no lesions are seen; b. shows the anterior retroflexed view - a large LSIL lesion is now apparent

the following:

"Should the retroflexion maneuver in the rectum be a standard of care for colonoscopy? The colonoscope in a straightforward-viewing mode is rarely able to identify the anal verge. It is true that identification of the anal verge is rarely of great importance for the performance of colonoscopy; however, if a retroflexion is performed, it is possible to obtain a close-up view of the distal-most part of the rectal ampulla and to see the dentate line and the fine vascular pattern down to that area of transition epithelium. It is also possible to visualize limited segments of proctitis or hemorrhoids in that region, and to identify flat adenomas that are not evident on straightforward inspection. There is an old adage that 'the more you look, the more you find'.

I believe that universal retroflexion should be the goal for everyone who performs colonoscopy, but there are circumstances where retroflexion is not indicated. The first is where the rectal vault is narrow, such as when radiotherapy has been delivered to the rectum and there is fibrosis and contraction. The second is in patients with ulcerative colitis who may have a scarred and narrowed rectum. In these patients, wide and deep lacerations may be provoked by the attempt to perform a rectal retroversion. All patients followed up for any postoperative problem with an ileoanal pouch should have a retroflexion performed, but the instrument should not be a standard colonoscope. In these patients a gastroscope can be used to excellent advantage because of its short bending radius and its short nose (distance from the tip of the fully bent instrument to the objective lens). Except in the aforementioned circumstances there is no risk in looking at the rectum in a retroflexed mode.

Having a colonoscopy should have the same meaning to everybody: that the cecum has been reached and inspected, that significant pathology has been sought, and that the endoscopist has performed retroflexion at the end of the examination to ensure completeness of the colonoscopic investigation [24]."

Most endoscopes in routine use today have NBI capability and high definition optics. These differences make it easier to view dysplastic lesions. Some also have magnifying capability. Thus the 'fine vascular pattern down to that area of transition epithelium' described by Waye in 1999 can be visualized even better with the endoscopes of 2018 .

\section{Conclusions}

Anal SIL can be detected by examination of the anoderm and ATZ during routine screening colonoscopy. Lesions detected can be better defined and ablated by chromoendoscopy using NBI and AA. Focused examination of the ATZ and anal canal and perianal skin during routine screening colonoscopy affords an opportunity to increase detection of anal SIL, the precursor to anal squamous cell carcinoma. Lesions detected can reproducibly be reidentified and ablated by chromoendoscopy with NBI and AA. In the words of Dr. Waye, 'the more you look, the more you find'.

\section{Acknowledgements}

The authors acknowledge with gratitude our colleagues who referred their patients in whom anal SIL was detected incidentally to us for further characterization and lesion ablation by chromoendoscopy (NBIA).

\section{References}

1. Chou YP, Saito Y, Matsuda T, Nakajima T, Mashimo Y, et al. (2009) Novel diagnostic methods for early-stage squamous cell carcinoma of the anal canal successfully resected by endoscopic submucosal dissection. Endoscopy 41: E283-E285. [Crossref]

2. Oono Y, Fu K, Nakamura H, Iriguchi Y, Yamamura A, et al. (2010) Narrowband imaging colonoscopy with a transparent hood for diagnosis of a squamous cell carcinoma in situ in the anal canal. Endoscopy 42: E183-E184. [Crossref]

3. Morisaki T, Isomoto H, Akazawa Y, Yamaguchi N, Ohnita K, et al. (2012) Beneficial use of magnifying endoscopy with narrow-band imaging for diagnosing a patient with squamous cell carcinoma of the anal canal. Dig Endos 24: 42-45. [Crossref]

4. Horimatsu T, Miyamoto S, Ezoe Y, Muto M, Yoshizawa A, et al. (2012) Gastrointestinal Case of early-stage squamous cell carcinoma of the anal canal diagnosed using narrowband imaging system with magnification. J Gastroenterol Hepatol 27: 1406.

5. Inkster MD, Wiland HO, Wu JS (2015) Detection of anal dysplasia is enhanced by narrow band imaging and acetic acid. Colorectal Dis 18: O17-O21. [Crossref]

6. Inkster MD, Wu JS (2017) Detection of anal dysplasia by chromoendoscopy with narrow band imaging and acetic acid (NBIA) in 182 patients. Clin Surg 2: 1583.

7. Darragh TM, Berry JM, Jay N, Palefsky JM. Ch 17 (2012) The anal canal and perianus HPV-related disease. In Modern Colposcopy, Textbook and Atlas, 3rd Ed., Mayeaux EJ Jr, Cox JT, editors, ASCCP. 2012: 484-538.

8. Darragh TM, Colgan TJ, Cox JT, Heller DS, Henry MR, (2012) The lower anogenital squamous terminology standardization project for HPV-associated lesions: Background and consensus recommendations from the College of American Pathologists and the American Society for Colposcopy and Cervical Pathology. Arch Pathol Lab Med 136: 1266-1297. [Crossref]

9. Munoz N, Castellsagué X, Berrington de González A, Gissmann L (2006) Chapter 1: $\mathrm{HPV}$ in the etiology of human cancer. Vaccine 24S3:S3/1-S3/10.

10. Stanley MA, Winder DM, Sterling JC, Goon PKC (2012) HPV infection, anal intraepithelial neoplasia (AIN) and anal cancer: current issues. BMC Cancer 12: 398.

11. Inkster MD, Szmulowicz UM, Wiland HO, Wu JS (2016) Anal condyloma and anal dysplasia. In Anorectal Disease, Zutshi M (ed). Springer 8: 189-209.

12. Cancer Stat Facts: Anal cancer. NIH, National Cancer Institute, Surveillance, 
Epidemiology, and End Results Program.

13. US Department of Veterans Affairs (2009) HIV/AIDS for Health Care Providers. Ana Dysplasia. Last reviewed/updated: October 28, 2011. http://www.hiv.va.gov/provider/ manual-primary-care/anal-dysplasia.asp" www.hiv.va.gov/provider/manual-primarycare/anal-dysplasia.asp Accessed July 29, 2018.

14. Suneson KG, Norgaard M, Thorlacius-Ussing O, Laurberg S (2010) Immunosuppressive disorders and risk of anal squamous cell carcinoma: a nationwide cohort study in Denmark, 1978-2005. Int J Cancer 127: 675-684. [Crossref]

15. Joseph DA, Meester RGS, Zauber AG, Manninen DL, Winges L, et al. (2016) Colorectal cancer screening: Estimated future colonoscopy need and current volume and capacity. Cancer 122: 2479-2486. [Crossref]

16. Nigro ND (1987) Multidisciplinary management of cancer of the anus. World J Surg 11: 446-451. [Crossref]

17. Fenger C, Nielsen VT (1986) Precancerous changes in the anal canal epithelium in resection specimens. Acta Path Microbiol Immunol Scand Sec A 94: 63-69. [Crossref]
18. Fenger C (1987) The anal transitional zone. Acta Pathol Microbiol Immunol Scand 95: 1-42. [Crossref]

19. Herrmann G, Desfosses L (1880) Sur la muqueuse de la région cloacale du rectum Comptes Rendus Hebdomadaires Séances l'Académie Sciences 90: 1301-1302.

20. Stroud BB. On the anatomy of the anus (1896) Ann Surg 24: 1-15. [Crossref]

21. Jabbour SK, Frassica D (2009) Anal cancer. In: Handbook of Radiation Oncology: Basic Principles and Clinical Protocols, Haffty BG, Wilson LD (eds), Jones and Bartlett Publishers, Sudbury.

22. Tanaka E, Noguchi T, Nagai K, Akashi Y, Kawahara K, et al. (2012) Morphology of the epithelium of the lower rectum and the anal canal in the adult human. Med Mol Morphol 45: 72-79. [Crossref]

23. Grobe JL, Kozarek RA, Sanowski RA (1982) Colonoscopic retroflexion in the evaluation of rectal disease. Am J Gastroenterol 77: 856-858. [Crossref]

24. Waye JD (1999) What constitutes a total colonoscopy? Am J Gastroenterol 94: 14291430. [Crossref]

Copyright: (C2018 Inkster MD. This is an open-access article distributed under the terms of the Creative Commons Attribution License, which permits unrestricted use, distribution, and reproduction in any medium, provided the original author and source are credited. 